\title{
Examples of molecular switching in inorganic solids, due to temperature, light, pressure, and magnetic field*
}

\author{
F. Varret ${ }^{1, \mp}$, A. Bleuzen ${ }^{2}$, K. Boukheddaden ${ }^{1}$, A. Bousseksou ${ }^{3}$, \\ E. Codjovi ${ }^{1}$, C. Enachescu ${ }^{1}$, A. Goujon ${ }^{1}$, J. Linares ${ }^{1}$, N. Menendez ${ }^{1,4}$, \\ and M. Verdaguer ${ }^{2}$ \\ ${ }^{1}$ Laboratoire de Magnétisme et d'Optique CNRS-Université de Versailles, 45 \\ Avenue des Etats-Unis, 78035 Versailles Cedex, France; ${ }^{2}$ Laboratoire de Chimie \\ Inorganique et Matériaux Moléculaires, CNRS-Université Pierre et Marie Curie, \\ 4 place Jussieu, 75252 Paris Cedex 05, France; ${ }^{3}$ Laboratoire de Chimie de \\ Coordination, CNRS, UPR 8241, 205 Route de Narbonne, 31017 Toulouse, \\ France; ${ }^{4}$ Departmento de Quimica Fisica Aplicada, Universidad Autonoma de \\ Madrid, 28049-Madrid, Spain
}

\begin{abstract}
We describe various molecular switching processes occurring in several types of inorganic solids: spin cross-over (SC) compounds, photomagnetic Prussian blue analogs (PBAs), and valence-tautomeric system. Their thermo-, photo-, piezo-, and magneto-chromic properties are illustrated by recent examples. A common description of their static properties by a two-level model is given.
\end{abstract}

\section{INTRODUCTION}

Molecular switching of inorganic solids closely relates to the vibronic lability of molecular units, previously introduced by J. A. Ammeter [1]. We report here on several families of inorganic systems [2] where a SC is involved in the switching process between the two molecular states: SC solids, PBAs, valence-tautomeric system (VT), see table below. A previous presentation of the underlying concept of "molecular bistability" was given by O. Kahn [3], on the example of SC solids. The bistable properties at the molecular level are adequately described through a molecular configurational diagram, i.e., a plot of the adiabatic energies vs. the distortion coordinate of the molecular system. Usually, for SC, a fully symmetric distortion is considered, associated with the change in average metal-ligand distance. Due to the large atomic displacements upon spin conversion, the optical properties drastically change, so that the switching properties can be followed as well by magnetic or optical (absorption, reflectivity) techniques. In Fig. 1, we show the configurational diagram suited to SC, in the case of the low-spin (LS) ground state. It is noteworthy that the effect of environment in molecular solids slightly affects the configurational diagram. For example, we display in Fig. 1 the effect of an external pressure, which increases the $E(\mathrm{HS})-E(\mathrm{LS})$ energy gap, and correlatively reduces the energy barrier of the high-spin (HS) state, so as to raise the equilibrium temperature $T_{1 / 2}$ (see next section) and to shorten the lifetime of the HS state [9].

\footnotetext{
*Lecture presented at the $5^{\text {th }}$ Conference on Solid State Chemistry (SSC 2002), Bratislava, Slovakia, 7-12 July 2002. Other presentations are published in this issue, pp. 2083-2168.

${ }^{\ddagger}$ Corresponding author: E-mail: varret@physique.uvsq.fr
} 
System Low-temperature state

High-temperature state

Basic refs.

\begin{tabular}{|c|c|c|c|}
\hline $\mathrm{SC} \mathrm{Fe}^{\mathrm{II}}\left(3 \mathrm{~d}^{6}\right)$ & $\mathrm{Fe}^{\mathrm{II}}{ }_{\mathrm{LS}}(S=0)=t_{2 g}{ }^{6}$ & $\mathrm{Fe}_{\mathrm{LS}}^{\mathrm{II}}(S=2)=t_{2 \mathrm{~g}}{ }^{4} e_{2 g}{ }^{2}$ & {$[4,5]$} \\
\hline $\mathrm{Fe}, \mathrm{Co}$ PBA & $\mathrm{Fe}^{\mathrm{II}}{ }_{\mathrm{LS}}(S=0) \mathrm{Co}_{\mathrm{LS}}^{\mathrm{IIII}}(S=0)$ & $\mathrm{Fe}^{\mathrm{III}}{ }_{\mathrm{LS}}(S=1 / 2) \mathrm{Co}_{\mathrm{HS}}^{\mathrm{II}}(S=3 / 2)$ & {$[6,7]$} \\
\hline VT Co semiquinone $^{\mathrm{a}}$ & $\mathrm{Co}^{\mathrm{III}}(S=0)\left(\mathrm{sq}^{\bullet}\right)(\mathrm{cat})$ & $\mathrm{Co}_{\mathrm{HS}}^{\mathrm{II}}(S=3 / 2)\left(\mathrm{sq}^{\bullet}\right)\left(\mathrm{sq}^{\bullet}\right)$ & [8] \\
\hline
\end{tabular}

${ }^{\mathrm{a} C}$ Complete formula: $\left[\mathrm{Co}(\mathrm{phen})(3,5-\mathrm{DTBSQ})_{2}\right] \cdot \mathrm{C}_{6} \mathrm{H}_{5} \mathrm{CH}_{3}$

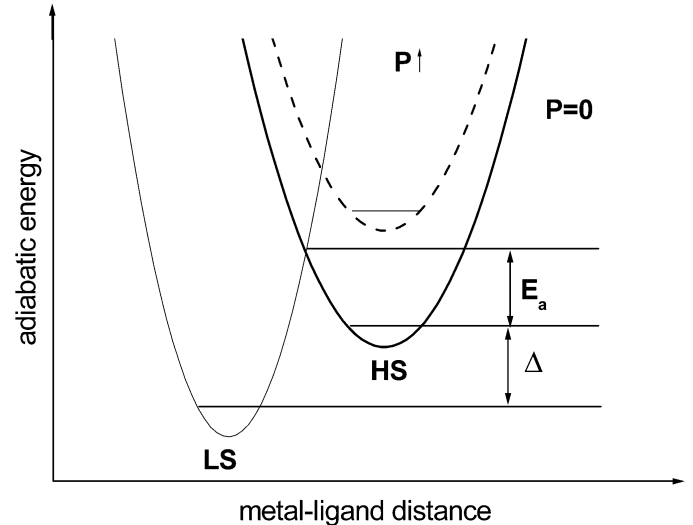

Fig. 1 The configurational diagram of spin cross-over (after ref. [4]), with the LS ground state, and the effect of an external pressure (after ref. [9]). Anharmonic effects have been discarded.

\section{ISING-LIKE MODEL}

A widely used model for such bistable systems is the Ising-like model, which describes interacting twolevel units, the energy levels of which have different energies and degeneracies. The two-level scheme indeed is a drastic simplification of the complete vibronic level scheme, in the adiabatic approximation (see, e.g., ref. [10]). However, it permits describing with qualitative success all quasi-static properties of the SC solids. The degeneracy ratio $g=g \mathrm{HS} / g \mathrm{LS}$, assumed to be temperature-independent, is related to the molar entropy change upon total conversion $\Delta S=\mathrm{R} \ln g$, and therefore can be derived from calorimetric measurements. A useful recent review of calorimetric data is given in ref. [11]. Because of both electronic and vibrational factors, $\Delta S>0$, therefore, $g>>1$. The Ising-like model has been used for describing the static [12] and dynamic [13] properties of SC solids, and was applied as well to the VT compound [2]. The Ising Hamiltonian writes:

$$
\hat{H}=(\Delta / 2) \sum_{i} \hat{\sigma}_{i}-J \sum_{<i, j>} \hat{\sigma}_{i} \hat{\sigma}_{j}
$$

with fictitious spins $\hat{\boldsymbol{\sigma}}$ having eigenvalues +1 in the HS state, -1 in the LS state, and degeneracies $g \mathrm{HS}$, $g \mathrm{LS}$, and $\Delta=E(\mathrm{HS})-E(\mathrm{LS})$ denoted energy gap (or "fictitious field") in the following. The HS fraction is expressed as a function of the "fictitious magnetization":

$$
n_{\mathrm{HS}}=(<\hat{\sigma}>+1) / 2
$$

A convenient form of the Ising-like Hamiltonian is the Ising equivalent form [10b], obtained by rewriting the canonical partition function to get rid of the pre-exponential factors. The Ising equivalent form involves a temperature-dependent energy gap (= "fictitious effective field") accounting for the degeneracy ratio:

$$
\hat{H}_{\text {equiv }}=\left(\Delta_{\text {eff }}(T) / 2\right) \sum_{i} \hat{\sigma}_{i}-J \sum_{<i, j>} \hat{\sigma}_{i} \hat{\sigma}_{j}
$$




$$
\Delta_{\text {eff }}(T)=\Delta-k_{\mathrm{B}} T \ln g
$$

The thermodynamic properties of the Ising-like system (with the LS ground state) are merely governed by the sign of the effective field, for example, the qualitative features of the thermal variation of the HS fraction are reported below. The equilibrium temperature $T_{1 / 2}$ for which $n_{\mathrm{HS}}=n_{\mathrm{LS}}=1 / 2$ corresponds to a null effective field, irrespectively of the interactions.

\begin{tabular}{lccl} 
Temperature & $T=0$ & $T=T_{1 / 2}$ & \multicolumn{1}{c}{$T>>T_{1 / 2}$} \\
\hline$\Delta_{\text {eff }}(T)$ & positive & 0 & negative \\
$<\hat{\sigma}>$ & -1 & 0 & $\left(g_{\mathrm{HS}}-g_{\mathrm{LS}}\right) /\left(g_{\mathrm{HS}}+g_{\mathrm{LS}}\right)$ \\
$n_{\mathrm{HS}}$ & 0 & $1 / 2$ & $g_{\mathrm{HS}}\left(g_{\mathrm{HS}}+g_{\mathrm{LS}}\right)$ \\
\hline
\end{tabular}

\section{THERMAL HYSTERESIS AND THERMAL SWITCHING}

The presence of interactions — of steric origin — makes the conversion curve $n_{\mathrm{HS}}(T)$ steeper around $T_{1 / 2}$. Above an interaction threshold value, the system becomes bistable at $T_{1 / 2}$, and thermal hysteresis occurs. The bistability condition is easily derived using the Ising equivalent form [14]: it requires the Ising equivalent system to be ordered at the equilibrium temperature, i.e., $T_{1 / 2}<T_{C}$. Then the reversal of $\Delta_{\text {eff }}(T)$ induces the reversal of non-null "fictitious magnetization" $<\hat{\sigma}>$, i.e.. the thermal transition is discontinuous (= first-order), and hysteresis can occur. The occurrence condition of hysteresis writes in mean-field treatment:

$$
J>k_{\mathrm{B}} T_{1 / 2}=\Delta / \ln g
$$

Equation 5 was previously derived from a "thermodynamic" model based on the properties of regular solutions in the Bragg-Williams approach [15], later shown to be formally equivalent to the meanfield two-level approach [16].

Thermal switching can be obtained by variation of temperature around $T_{1 / 2}$, provided that the relaxation between the two states is fast enough. The kinetic contribution so far observed for the hysteresis of SC solids, on the time scale of some minutes, can be attributed to heat-transfer problems.

Actually, there are no available data for the intrinsic kinetics of the SC phase transition, which seems to be rapid, and therefore should be difficult to disentangle from heat-transfer effects. On the other hand, the escape time of the metastable phase at the equilibrium temperature is expected to be rather long [14], in agreement with the existence of a quasi-static hysteresis at the experimental time scale (hours, days). Due to the slower relaxation in PBAs [17], the first-order thermal transition exhibited by Na-PBA [6] should be accompanied by large kinetic effects. As a matter of fact, there are some examples [18] of an easy trapping of the high-temperature phase (if different from the low-temperature phase) by thermal quenching. A model for kinetic thermal hysteresis, accounting for the relaxation rates, can be found in ref. [13a].

We briefly comment on the shape of the hysteresis loop. Indeed, the usual mean-field models result in well-rounded turning points of the loop, while most of experimental data display well-marked turning points, with sometimes rather bent sides (instead of the expected jumps). The bent sides are easily reproduced by a distribution of transition temperatures. The origin of the well-marked turning points was recently elucidated [20] thanks to improved models including both long- and short-range interactions $[13 \mathrm{c}]$.

An interesting question concerns the supposed ferrodistortive spin-like domains, which have not been observed directly, so far. Their existence was inferred [21] from X-ray diffraction experiments and from the existence of minor hysteresis loops, see Fig. 2. Minor loops can be modeled by analogy to magnetic domains (Preisach models) [22]. 


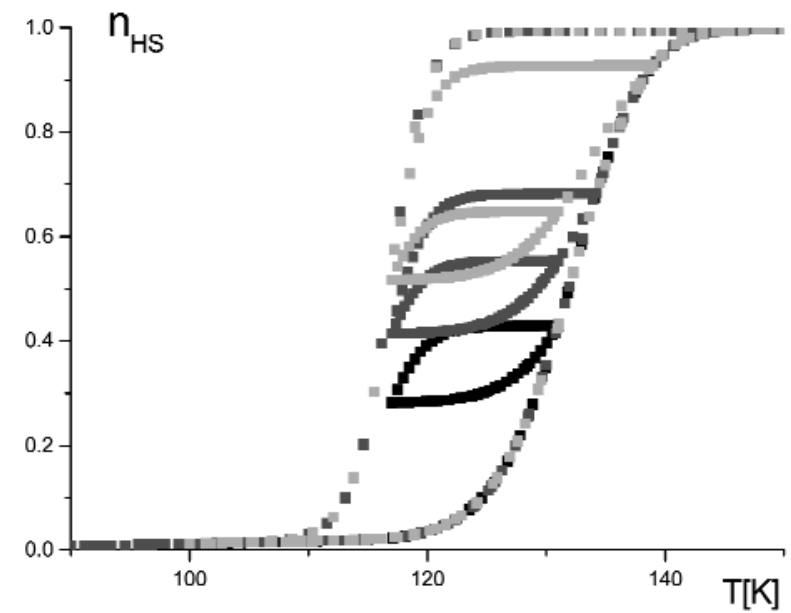

Fig. 2 Major and minor hysteresis loops, for the $\mathrm{SC}$ solid $\left[\mathrm{Fe}(\mathrm{btr})_{2}(\mathrm{NCS})_{2}\right] \mathrm{H}_{2} \mathrm{O}$ (after ref. [22]).

\section{OPTICAL SWITCHING}

Photoexcitation at low temperature, with adequate wavelength, may provide a reversible switching of the system. This is based on the long lifetime of the excited state at low temperature, and, therefore, the effect was named light-induced excited spin-state trapping (LIESST) [23], when discovered on the example of SC. The photoprocess involves either a metal-to-ligand charge transfer (MLCT) or d-d transitions. For typical Fe $\mathrm{II}^{\mathrm{II}}$ compounds, absorption bands for the LS $\rightarrow$ HS process are located at $\sim 500$ (MLCT), $550(\mathrm{~d}-\mathrm{d}$ ), and $1000(\mathrm{~d}-\mathrm{d}) \mathrm{nm}$. The reverse process (HS $\rightarrow$ LS) occurs by irradiation at $\sim 750 \mathrm{~nm}$, with, however, a lesser efficiency, due to branching ratio of $\sim 4: 1$ for the direct and reverse processes, respectively. The reversibility of the photoprocess is, of course, appealing for applications to optical information storage, and similar effects have been reported for the PBAs [6]. In the case of SC, photoexcitation usually occurs as a bleaching effect [23b], for both the direct and reverse processes [2]. A useful scheme is the Jablonski diagram, which has been reproduced many times, see ref. [23]. The quantum yield of the photoprocess has been measured recently, in the case of the SC salt $\mathrm{Fe}(\mathrm{ptz})_{6}\left(\mathrm{BF}_{4}\right)$, and was found close to unity [24]. Therefore, the photoprocess is considered as a singlemolecule process. In the case of a binuclear SC solid, the photoprocess induces at once the transformation LS-LS $\rightarrow$ HS-HS [25]. As for the PBAs, the suitable wavelength $(\sim 750 \pm 100 \mathrm{~nm})$ is broad and seems to be an intervalence band [17], the optical properties are complex and result either in bleaching or in photodarkening, according to the nature of the alkali cation and the wavelength [18]. We show in Fig. 3 experimental data for $\mathrm{Rb}-\mathrm{Co}-\mathrm{Fe}$ PBA, showing a photodarkening effect. A large effect of bulk absorption of light is inferred from the different kinetics of the magnetic and reflectivity signals $[17,26]$.

The photoexcitation process may be limited by several factors, in addition to trivial absorption of light: (i) by an opposite light-induced effect (e.g., the reverse LIESST at $750 \mathrm{~nm}$ in SC solids is very often associated with some direct effect due to the overlapping with the bands centered at 550 and $1000 \mathrm{~nm}$ ) and (ii) by the relaxation of the photoexcited state. In both cases, a photostationary state is generated at long times (see below). Another intriguing point, detectable in many photoexcitation kinetic data, is the frequent observation of an incubation stage [27,28], an effect reminiscent of some solid-state first-order transitions (cooperative photoprocess? [29]). Such effects remain to be elucidated in the general frame of a photoexcitation process that has little sensitivity to environment effects.

An alternative route to photoswitching was recently proposed by the use of photoisomerizable ligands around the SC unit. The effect denoted ligand driven light-induced spin crossover (LD-LISC, [41]) has proved to be efficient at room temperature. 


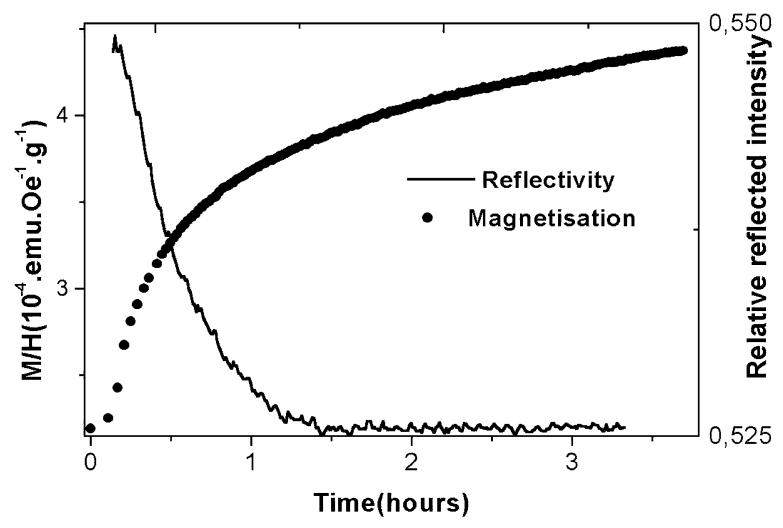

Fig. 3 Photoexcitation of $\mathrm{Rb}_{0.52} \mathrm{Co}\left[\mathrm{Fe}(\mathrm{CN})_{6}\right]_{0.84}, 2.3 \mathrm{H}_{2} \mathrm{O}$ detected by magnetic and reflectivity measurements (after refs. [17,26]).

Recent experiments have shown that the optical switching of SC solids was also possible in the thermal hysteresis loop, thanks to nanosecond laser pulses [30]. Indeed, the thermal relaxation of the photoexcited state is extremely fast at high temperatures, so that a very high flux of light is needed. Working in the hysteresis loop should help slow down the relaxation rates, due to cooperative interactions (see ref. [14] for model). In such a case, the physical features are indeed those of a first-order transition triggered by an external stimulus, and the single-molecule excitations, occurring in sufficient number, might create the critical germs needed for nucleation and growth of the photoinduced phase [31].

Thermal switching can also occur under permanent light and at low temperature, when the photoexcitation and the thermal relaxation of the photoexcited state compete against each other. A suitable phenomenological master equation is written:

$$
d n_{\mathrm{HS}} / d t=\left(1-n_{\mathrm{HS}}\right) I_{0} \sigma-n_{\mathrm{HS}} k_{\mathrm{HL}}\left(T, n_{\mathrm{HS}}\right)+\left(1-n_{\mathrm{HS}}\right) k_{\mathrm{LH}}\left(T, n_{\mathrm{HS}}\right)
$$

where $I_{0}$ is the intensity of light, $\sigma$ is a factor accounting for absorption cross sections, quantum yield..., $k_{\mathrm{HL}}$ and $k_{\mathrm{LH}}$ are the transition rates for the $\mathrm{HS} \rightarrow \mathrm{LS}$ and LS $\rightarrow$ HS spontaneous relaxation. Assuming for simplicity a temperature-independent photoexcitation term, the monotonous temperature dependence of the relaxation rates leads to a light-induced equilibrium temperature [13b]. In the thermal activation regime, neglecting the spontaneous LS $\rightarrow$ HS relaxation (for low temperature) it writes, irrespective of the interactions:

$$
k_{\mathrm{B}} T_{1 / 2}^{*}=E_{\mathrm{A}}\left(n_{\mathrm{HS}}=1 / 2\right) / \ln \left(k_{\infty} / I_{0} \sigma\right)
$$

It is noteworthy that the low-temperature steady state is HS-rich (slow relaxation of the photoexcited state), while the high-temperature steady state is LS-rich (fast relaxation). Therefore, under permanent light, the steady state exhibits an HS $\rightarrow$ LS conversion at $T_{1 / 2} *$. Due to cooperativity, an instability can occur at $T_{1 / 2} *[32,33]$. The mechanism was described through a mean-field macroscopic master equation [33,34], which accounts for linear photoexcitation (i.e., with a constant quantum yield), and nonlinear, self-accelerated relaxation [35]. The mean-field macroscopic master equation writes, neglecting the spontaneous LS $\rightarrow$ HS relaxation (for low temperature):

$$
d n_{\mathrm{HS}} / d t=\left(1-n_{\mathrm{HS}}\right) I_{0} \sigma-n_{\mathrm{HS}} k_{\infty} \exp \left(-E_{\mathrm{A}} / k_{\mathrm{B}} T\right) \exp \left(-\alpha n_{\mathrm{HS}}\right)
$$

where $E_{\mathrm{A}}$ and $\alpha$ respectively are the activation energy barrier and the Hauser self-acceleration factor (proportional to the interaction parameter $J$ ). 
Instability occurs as soon as the self-acceleration factor is in excess of the threshold value $\alpha=4$, and gives rise to hysteretic behaviors, as a function of temperature, pressure, and light intensity. Such hystereses have been denoted LITH, LIPH, and LIOH (respectively, light-induced thermal, pressure, and optical hysteresis). In Fig. 4, we show the first example of LITH, best observed by reflectivity technique, which only probes the top layers of the absorbing sample [26]. An important consequence of these nonlinear effects is the occurrence of an intensity threshold [33], which may severely hinder the photoswitchability of absorbing materials, such as the PBAs, for instance.

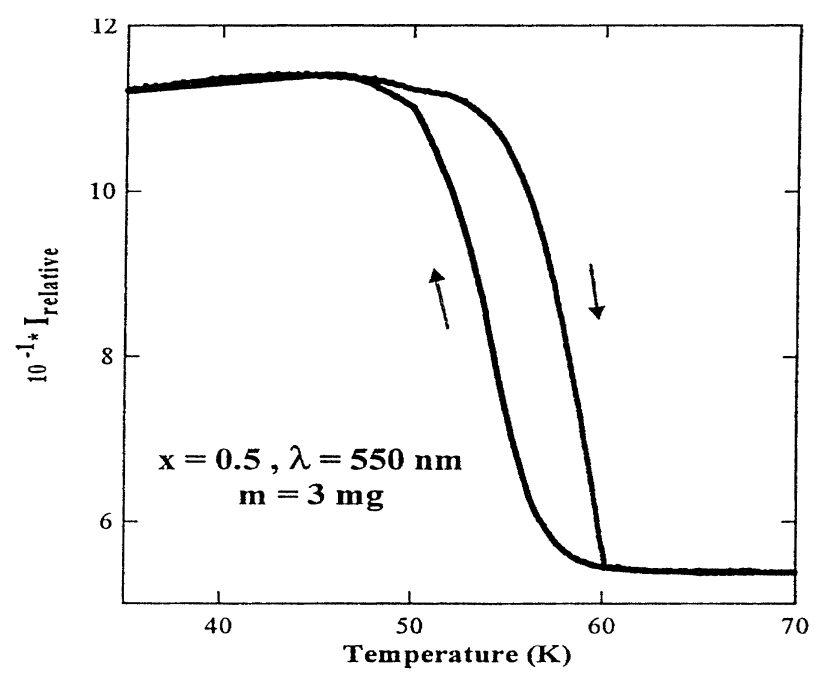

Fig. $4 \mathrm{LITH}$, from magnetic and reflectivity data, for the $\mathrm{SC}$ solid $\left[\mathrm{Fe}_{0.50} \mathrm{Co}_{0.50}(\mathrm{btr})_{2}(\mathrm{NCS})_{2}\right] \mathrm{H}_{2} \mathrm{O}$ under permanent light $\left(550 \mathrm{~nm}, 20 \mathrm{~mW} / \mathrm{cm}^{2}\right)$. The loop was completed within $14 \mathrm{~h}$ (after ref. [33]).

\section{PRESSURE SWITCHING}

Pressure favors the LS state of smaller volume. The pressure dependence of the energy gap $\Delta=E(\mathrm{HS})-E(\mathrm{LS})$ merely writes:

$$
\Delta(p)=\Delta(0)+p \delta V
$$

with $\delta V$, the molecular volume increase upon spin conversion, leading to:

$$
T_{1 / 2}(p)=T_{1 / 2}(0)+p \Delta V / \Delta S,
$$

where $\Delta V=N \delta V$ is the molar volume increase upon total conversion. Most of the experimental data $[2,9,36]$ for the considered families of compounds yield $\delta V \sim 20-30 \AA^{3}$. In Figs. 5 and 6, we show typical pressure experiments. 


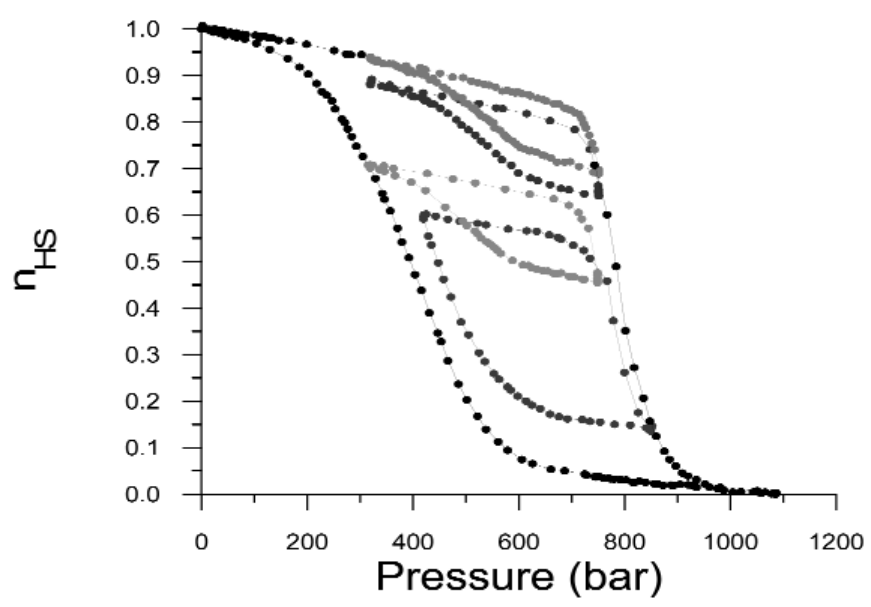

Fig. 5 Major and minor pressure hysteresis loops recorded at $T=147 \mathrm{~K}$ for the SC solid $\left[\mathrm{Fe}_{0.66}{ }^{\mathrm{Ni}_{0.34}}(\mathrm{btr})_{2}(\mathrm{NCS})_{2}\right] \cdot \mathrm{H}_{2} \mathrm{O}$, using optical reflectivity detection $(\lambda=600 \mathrm{~nm})$.

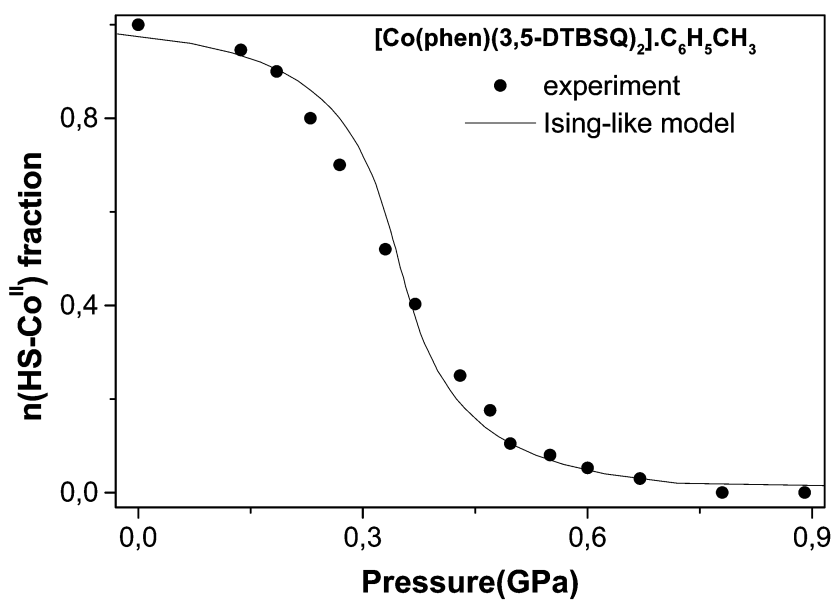

Fig. 6 The pressure-induced valence tautomeric transition, from $\operatorname{Co}\left(\mathrm{sq}^{\bullet}\right)_{2}$ (high-temperature phase) to $\operatorname{Co}\left(\mathrm{sq}^{\bullet}\right)(\mathrm{cat})$ (low-temperature phase). Experimental data from ref. [37]. The full line was computed using the Ising-like model, with a single adjustable parameter, $\delta V \sim 27 \AA^{3}$ (after ref. [2]).

\section{MAGNETIC SWITCHING}

Recent experiments $[38,39]$ under pulsed magnetic field up to 35 Tesla, using reflectivity detection, have shown the partial or complete triggering of the SC transition by the magnetic field, see Fig. 7.

Major conclusions of the experiment are the following: (i) the transition can be (partially) triggered only when the initial state of the system belongs to the metastable ascending branch of the thermal hysteresis loop; this was adequately discussed in ref. [38]; (ii) the out-of-phase response of the sample to the magnetic excitation shows the kinetic character of the process. This kinetic character is thought to be responsible for the incompleteness of the transition. Further experiment on a Co-based SC solid (faster relaxation) provided a complete triggering of the transition [39]. The simple equation was derived for the isothermal process [38], in the high-temperature approximation (paramagnetic Curie law). The magnetic molar free energy writes: 

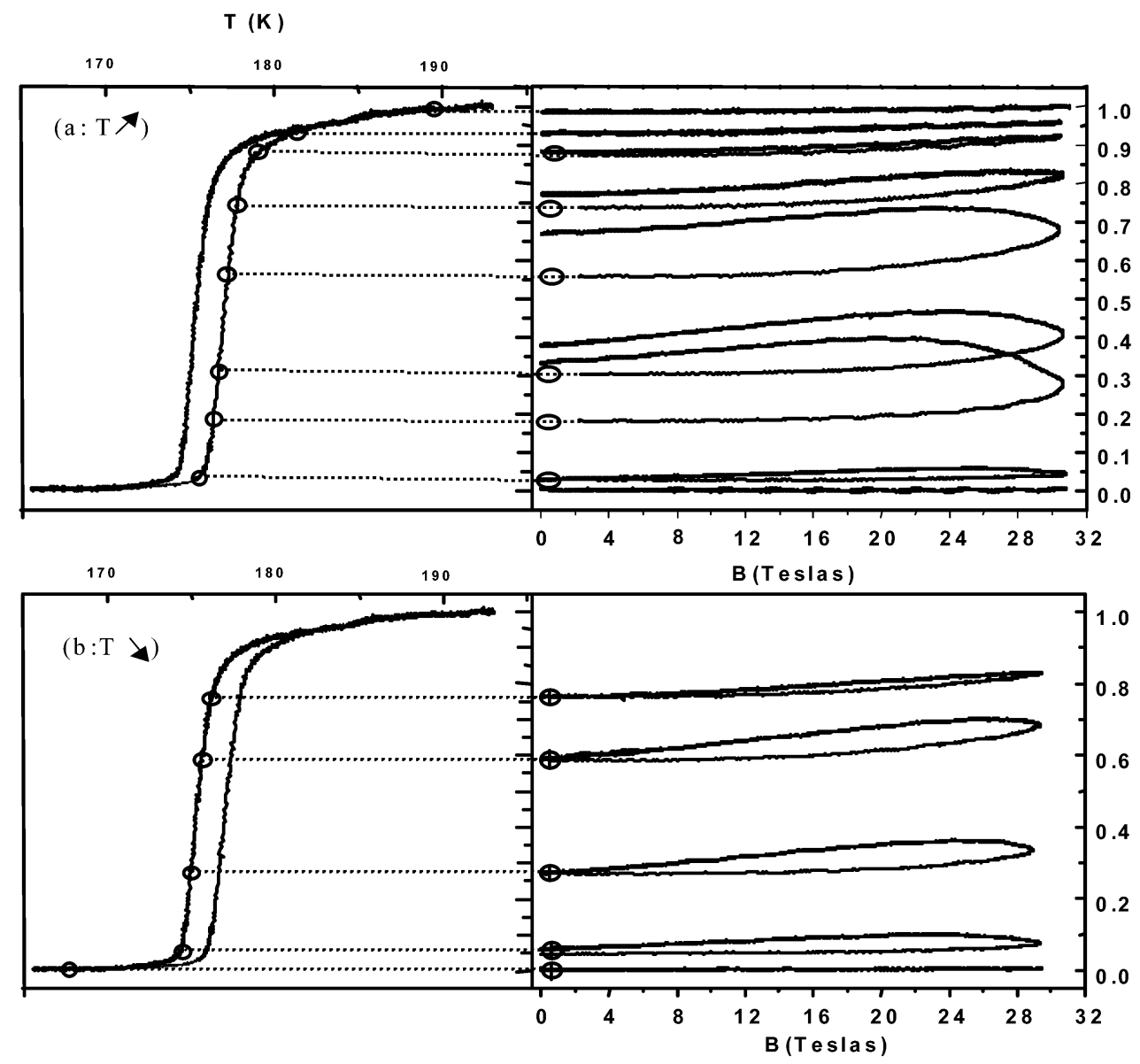

Fig. 7 The SC solid $\mathrm{Fe}(\text { phen })_{2}(\mathrm{NCS})_{2}$ : the complete set of pulsed-field experiments in the ascending (a) and descending (b) branches of the thermal hysteresis loop. Initial states are shown by circles (after ref. [38], from reflectivity data).

$$
\Delta G=G_{\mathrm{HS}}-G_{\mathrm{LS}}=\Delta H(0)-T \Delta S(0)-\left(\chi_{\mathrm{HS}}-\chi_{\mathrm{LS}}\right) B^{2} / 2 \mu_{0}
$$

where $\Delta H(0), \Delta S(0)$ refer to the properties in absence of an external field. Accounting for the paramagnetic properties of the HS state, it comes for a spin $S=0 \rightarrow S=2$ transition:

$$
\begin{gathered}
T_{1 / 2}(B)=T_{1 / 2}(0)-4\left(\mu_{\mathrm{B}} B\right)^{2} / k_{\mathrm{B}} \Delta(0) \\
\Delta(B)=\Delta(0)-4(\ln g)\left(\mu_{\mathrm{B}} B\right)^{2} / \Delta(0)
\end{gathered}
$$

The negative sign for the gap shift means that the HS state is favored by the coupling to the magnetic field. The peak value of the applied magnetic field (31 T) corresponds to a computed shift of the transition temperature $\Delta T_{1 / 2} \sim-1.8 \mathrm{~K}$, a sufficient shift for a complete triggering to be expected in the quasi-static regime. Therefore, the incompleteness of the triggering was interpreted as due to the kinetic aspect of the pulsed-field experiment. These aspects were recently modeled through dynamic treatments of the Ising-like model $[39,40]$. 


\section{PERSPECTIVES}

Molecular switchability is promising in terms of information storage and photocontrol of magnetic and optical properties. However, most of the knowledge obtained so far deals with the low-temperature properties. Present efforts aim to raise the working temperature of these photoprocesses, until room temperature, and to trigger the transition by brief pulses of light, in the thermal hysteresis interval. A true understanding of the photoprocess will certainly require a solid-state approach of the SC transition.

\section{ACKNOWLEDGMENTS}

We thank M. Nogues, J. Jeftic, and M. Goiran for scientific contributions, A. Wack for technical assistance, the Spanish government for N. Menendez's postdoctoral grant, NATO for a Cooperative Linkage Grant, and CNRS and EEC (TMR TOSS program ERB-FMRX-CT98-0199) for financial support.

\section{REFERENCES}

1. J. H. Ammeter. Nouv. J. Chim. 4, 631 (1980).

2. F. Varret, M. Nogues, A. Goujon. In Magnetism: Molecules to Materials, Vol. 2, J. Miller and M. Drillon (Eds.), p. 257, Wiley-VCH, New York (2001).

3. O. Kahn. Molecular Magnetism, VCH, New York (1993).

4. H. Toftlund. Coord. Chem. Rev. 94, 67 (1989); E. König. Struct. Bonding (Berlin) 76, 51 (1991).

5. P. Gütlich. Struct. Bonding (Berlin) 44, 83 (1981); P. Gütlich, A. Hauser, H. Spiering. Angew. Chem., Int. Ed. Engl. 33, 2024 (1994).

6. O. Sato, T. Iyoda, A. Fujishima, K. Hashimoto. Science 272, 704 (1996); O. Sato, T. Iyoda, A. Fujishima, K. Hashimoto. J. Electrochem. Soc. 144, L11 (1997).

7. A. Bleuzen, C. Lomenech, V. Escax, F. Villain, F. Varret, C. Cartier dit Moulin, M. Verdaguer. J. Am. Chem. Soc. 122, 6648 (2000); see also: C. Cartier, F. Villain, A. Bleuzen, M.-A. Arrio, P. Sainctavit, C. Lomenech, F. Baudelet, E. Dartyge, J.-J. Gallet, M. Verdaguer. J. Am. Chem. Soc. 122, 6653 (2000); V. Escax, A. Bleuzen, C. Cartier dit Moulin, F. Villain, A. Goujon, F. Varret, M. Verdaguer. J. Am. Chem. Soc. 123, 12536 (2001).

8. D. M. Adams, A. Dei, A. L. Rheingold, D. N. Hendrickson. J. Am. Chem. Soc. 115, 8221 (1993); see also: D. M. Adams et al. Angew. Chem., Int. Ed. Engl. 34, 1481 (1995) and J. Am. Chem. Soc. 118, 11515 (1996).

9. J. Jeftic, H. Romstedt, A. Hauser. J. Phys. Chem. Solids 57, 1743 (1996); see also: E. König, G. Ritter, S. K. Kulshreshtha, J. Waigel, H. A. Goodwin. Inorg. Chem. 23, 1896 (1984); J. Zarembowitch, C. Roux, M.-L. Boillot, R. Claude, J. P. Itié, A. Pollan, M. Bolte. J. Mol. Cryst. Liq. Cryst. 234, 247 (1993); J. Jeftic, N. Menéndez, A. Wack, E. Codjovi, J. Linarès, A. Goujon, G. Hamel, Stefan Klotz, G. Syfosse, F. Varret. Meas. Sci. Technol. 10, 1059 (1999); M.-L. Boillot, J. Zarembowitch, J.-P. Itié, A. Pollan, E. Bourdet, J. G. Haasnoot. New J. Chem. 26, 313 (2002).

10. (a) J. Wajnflasz and R. Pick. J. Physique 32, C1-91 (1971); (b) S. Doniach. J. Chem. Phys. 68, 4912 (1978).

11. M. Soraï. Chem. Soc. Jpn. 74, 2223 (2001).

12. A. Bousseksou, J. Nasser, J. Linares, K. Boukheddaden, F. Varret. J. Physique I 2, 1381 (1992) and 3, 1463 (1993); A. Bousseksou, H. Constant, F. Varret. J. Physique I 5, 747 (1995).

13. (a) K. Boukheddaden, I. Shteto, B. Hôo, F. Varret. Phys. Rev. B 62, 14796, 14806 (2000); (b) B. Hôo, K. Boukheddaden, F. Varret. Eur. Phys. J. B 17, 449 (2000); (c) K. Boukheddaden, J. Linares, H. Spiering, F. Varret. Eur. Phys. J. B 15, 317 (2000).

14. I. Shteto, K. Boukheddaden, F. Varret. Phys. Rev. E 60, 5139 (1999).

15. C. P. Slichter and H. G. Drickamer. J. Chem. Phys. 56, 2142 (1972).

16. R. Zimmermann and R. König. J. Phys. Chem. Solids 38, 779 (1977). 
17. A. Goujon, O. Roubeau, M. Noguès, F. Varret, A. Dolbecq, M. Verdaguer. Eur. Phys. J. B 14, 115 (2000).

18. A. Goujon, F. Varret, V. Escax, A. Bleuzen, M. Verdaguer. Polyhedron 20, 1339, 1347 (2001).

19. S. Salunke, K. Boukheddaden, E. Codjovi, J. Linares, F. Varret. Work in progress.

20. J. Linares, H. Spiering, F. Varret. Eur. Phys. J. B 10, 271 (1999).

21. E. König, B. Kannelopoulos, B. Powietzka, J. Nelson. J. Chem. Phys. 22, 9195 (1993); see also: A. Ozarowzki et al. Inorg. Chem. 30, 3167 (1991).

22. H. Constant-Machado, A. Stancu, J. Linarès, F. Varret. IEEE Trans. Magn. 34, 2213 (1998).

23. (a) S. Decurtins, P. Gütlich, H. Spiering, A. Hauser. Inorg. Chem. 24, 2174 (1985); (b) A. Hauser. Chem. Phys. Lett. 124, 543 (1986); (c) A. Hauser. Comments Inorg. Chem. 17, 17 (1995).

24. C. Enachescu, U. Oetliker, A. Hauser. J. Phys. Chem. B 106, 9540 (2002).

25. J. F. Létard, J. A. Real, N. Moliner, A. B. Gaspar, L. Capes, O. Cador, O. Kahn. J. Am. Chem. Soc. 121, 10630 (1999); see also G. Chastanet et al. Chem. Commun. 819 (2001); V. Ksenofontov et al. J. Phys. Chem. B 105, 12266 (2001); V. Ksenofontov et al. Chem. Phys. Lett. 348, 381 (2001)

26. E. Codjovi, W. Morscheidt, J. Jeftic, J. Linares, M. Nogues, A. Goujon, O. Roubeau, H. ConstantMachado, A. Desaix, A. Bousseksou, M. Verdaguer, F. Varret. J. Mol. Cryst. Liq. Cryst. 335, 1295 (1999).

27. C. Enachescu, H. Constant-Machado, E. Codjovi, K. Boukheddaden, J. Linarès, F. Varret. J. Phys. Chem. Solids 62, 1409 (2001).

28. Y. Ogawa, A. Mino, S. Koshihara, K. Koshino, T. Ogawa, C. Urano, H. Takagi. Phys. Rev. Lett. 84, 3181 (2000).

29. S. Koshihara, Y. Takahashi, H. Sakai, Y. Tokura, T. Luty. J. Phys. Chem. B 103, 2592 (1999).

30. E. Freysz and J.-F. Létard. Private communication.

31. S. Koshihara, Y. Tokura, T. Mitani, G. Saito, T. Koda. Phys. Rev. B 42, 6853 (1990).

32. J. F. Letard, P. Guionneau, L. Rabardel, J. A. K. Howard, A. E. Goeta, D. Chasseau, O. Kahn. Inorg. Chem. 37, 4432 (1998).

33. A. Desaix, O. Roubeau, J. Jeftic, J. G. Haasnoot, K. Boukheddaden, E. Codjovi, J. Linares, M. Nogues, F. Varret. Eur. Phys. J. B 6, 183 (1998).

34. F. Varret, K. Boukheddaden, J. Jeftic, O. Roubeau. J. Mol. Cryst. Liq. Cryst. 335, 1273 (1999).

35. A. Hauser, P. Gütlich, H. Spiering. Inorg. Chem. 25, 4345 (1986); A. Hauser. J. Chem. Phys. 94, 2741 (1991); A. Hauser, J. Jeftic, H. Romstedt, R. Hinek, H. Spiering. Coord. Chem. Rev. 190-192, 471 (1999).

36. E. Codjovi, N. Menendez, J. Jeftic, F. Varret. C. R. Acad. Sci. 4, 181 (2001).

37. C. Roux, D. M. Adams, J. P. Itié, A. Polian, D. N. Hendrickson, M. Verdaguer. Inorg. Chem. 35, 2846 (1996).

38. A. Bousseksou, N. Negre, M. Goiran, L. Salmon, J.-P. Tuchagues, M.-L. Boillot, K. Boukhedaden, F. Varret. Eur. Phys. J. B 13, 451 (2000); see also: N. Negre, M. Goiran, S. Ashkenzay, A. Bousseksou, J. Haasnoot, K. Boukheddaden, F. Varret. Synth. Met. 115, 289 (2000) and A. Bousseksou, K. Boukheddaden, M. Goiran, C. Consejo, J.-P. Tuchagues. Phys. Rev. $B$ 65, 172412 (2002).

39. A. Bousseksou, K. Boukheddaden, M. Goiran, C. Consejo, J.-P. Tuchagues. Phys. Rev. B 65, 1724 (2002).

40. Y. Ogawa, T. Ishikawa, S. Koshihara, K. Boukheddaden, F. Varret. Phys. Rev. B (2002). In press.

41. M. L. Boillot, S. Chantraine, J. Zarembowitch, J. Y. Lallemand, J. Prunet. New J. Chem. 2, 179 (1999); A. Sour, M. L. Boillot, E. Rivière, P. Lesot, Eur. J. Inorg. Chem. 2117 (1999). 